\title{
The current situation and relationship of positive psychological qualities and well-being of employees in Enterprises
}

\author{
Jun Luo ${ }^{1}$, Yulan $\mathrm{Yu}^{2, \mathrm{a}}$ and Ying $\mathrm{Yu}^{3}$ \\ ${ }^{1}$ Department of Management, Guangdong University of Science \& Technology, Dongguan 523083, China \\ ${ }^{2}$ Department of Psychology/ Center Quality of Life and Applied Psychology, Guangdong Medical University, Dongguan 523808, China \\ ${ }^{3}$ School of foreign languages, Xiangtan University, Xiangtan 411105, China
}

\begin{abstract}
To investigate the status and relationship of positive psychological qualities and well-being of employees in Enterprises Methods 342 employees were tested by the Life Orientation Test Revised (LOT-R), Adult Dispositional Hope Scale (ADHS), General Self-Efficacy Scale (GSES) and Oxford Happiness Test-Revised (ROHS). Results (1) the scores of Optimistic, self-efficacy, hope and subjective well-being were (21.72 \pm 3.17$),(26.33 \pm 5.03),(24.24 \pm 3.21)$ and $(39.61 \pm$ 9.90). (2) In the optimism aspect, there was no significant difference between male and female, but there were significant differences based on marriage $(\mathrm{t}=2.82, \mathrm{p}<0.01)$, if only child $(\mathrm{t}=2.78, \mathrm{p}<0.01)$ and grow place $(\mathrm{t}=2.79, \mathrm{p}<0.01)$. In the hope and self-efficacy aspects, there was no significant difference based on gender, marriage, if only child and grow place. In the well-being aspect, the score of urban employees was higher than that of rural employees $(t=2.50, p<0.05)$ and there was no differences in other factors. (3)There were significant positive correlation between optimism, self-efficacy, hope and well-being $(\mathrm{r}=0.42,0.47,0.40, \mathrm{p}<0.01)$. (4) Supposing the subjective well-being as independent respectively, and hope, optimism, self-efficacy as dependents, we can get an regression equations. Explain rates of optimism and self-efficacy to well-being were $34.1 \%$. Conclusion Optimism and self-efficacy were positively correlated with well-being, no matter considered alone or together.
\end{abstract}

\section{Introduction}

With the rise of positive psychology and human centered management, Managers or operators of enterprises constantly think about their own competitive advantages and consider how to develop employees' positive mental qualities to play their potential to achieve the best working performance when they pursuit excellences. The positive psychological qualities of employees, such as optimism, hope, self-efficacy and happiness, are more and more concerned by researchers. Studies showed staffs with a high sense of well-being were more likely to experience happiness in work and life and faced the difficulties and challenges calmly. Well-being was a positive predictor on job performance [1]. What was the current situation of well-being of enterprise staffs, which was one of the issues to be discussed in this paper. Optimism, hope and self-efficacy are the core of the positive psychological capital. For college students, hope, optimism and self-efficacy can significantly predict happiness $[2,3]$. That is to say, improving these three aspects of positive psychological qualities can improve their happiness. How about Enterprise employees? What are the level of their optimism, hope, self efficacy and well-being? And what kind of relationships is between them? The present study researched the status quo and relationship of the enterprise staff's optimism, hope, self-efficacy and well-being.

\section{Research objects and methods}

\subsection{Research objects}

In this paper, a random sampling method was adopted to extract 400 employees in Guangdong Province, and the effective questionnaires were 342 (effective rate was $85.50 \%$ ). There were 202 males and 140 females, and all of them voluntarily participate in the tests with informed consent.

\subsection{Research tools}

\subsubsection{The Life Orientation Test Revised (LOT-R)}

Scheier et al developed tools to measure the dispositional optimism-the life orientation test (LOT). There were 8 items, including 4 positive and 4 negative items using 5 point Likert standard for evaluation. In 1994, Scheier et al revised the LOT and got the Life Orientation Test Revised (LOT-R), including 6 items, and the points were summed up to get the total scores [4]. Lai et al, researcher of City University of Hong Kong, found that LOT-R was more

\footnotetext{
a Corresponding author: yuyulan@gdmu.edu.cn
} 
brief, but it's psychometric properties was better than LOT [5], so this paper used LOT-R.

\subsubsection{Adult Dispositional Hope Scale (ADHS)}

There were 12 items in ADHS using 4 point Likert standard for evaluation. 4 items (No. 1, 4, 6, 8) belonged to pathways thinking, 4 items (No. 2, 9, 10, 12) belonged to agency thinking, and the others were used to transfer the attention which did not be summed up the scores [6-8].

\subsubsection{General Self-Efficacy Scale (GSES)}

There were 10 items in GSES using 4 point Likert standard for evaluation, which measured individual's self-confidence when one encountered setbacks or difficulties.

\subsubsection{Oxford Happiness Test-Revised (ROHS)}

Oxford Happiness Test-Revised (ROHS) was developed by Zheng (2009) [9] which contained 29 items using 4 point Likert standard for evaluation. It's internal consistency reliability reached 0.85 and test-retest reliability interval 6 months was 0.67 . ROHS was widely used in the UK.

\subsection{Research Methods}

This present study adopted questionnaires survey and the participants answered the questions one by one according to the truth and did not be interfered with others to answer all the questions. The answers were no "right" or "wrong". The questionnaires were returned at once when the participants finished them.

\subsection{Statistical methods}

The data were analyzed by SPSS 19.0. This paper adopted these statistical methods, such as independent samples t-test, single sample t-test, Pearson correlation, stepwise regression analysis.

\section{Results}

\subsection{The status quo of positive psychological qualities and well-being of employees in enterprises}

The scores of enterprise employees' optimism, self-efficacy, hope and well-being were (21.72 \pm 3.17$)$ 、

$(26.33 \pm 5.03) 、(24.24 \pm 3.21)$ and $(39.61 \pm 9.90)$

\subsection{A comparison of demographic data of positive psychological qualities and well-being of employees in enterprises}

Table 1 told us, In the optimism, there was no significant difference between male and female, but there were significant differences based on marriage, if only child and grow place. In the hope and self-efficacy, there was no significant difference based on gender, marriage, if only child and grow place. In the well-being, the score of urban employees was higher than that of rural employees and there was no differences in other factors.

\subsection{The relationship between positive psychological qualities and wellbeing of employees in Enterprises}

\subsubsection{Correlation analyses of positive psychological qualities and well-being}

From the above table, we can see that the staff's optimism, hope, self-efficacy and well-being were significantly positive correlated.

\subsubsection{Regression analysis of positive psychological qualities and well-being}

Table 1. The differences of positive psychological qualities and well-being

\begin{tabular}{|c|c|c|c|c|}
\hline & optimism & hope & self-efficacy & well-being \\
\hline Male & $21.94 \pm 3.10$ & $24.43 \pm 3.08$ & $26.70 \pm 4.77$ & $39.94 \pm 9.63$ \\
\hline Female & $21.31 \pm 3.28$ & $23.90 \pm 3.46$ & $25.63 \pm 5.46$ & $38.97 \pm 10.44$ \\
\hline $\mathrm{t}$ & 1.53 & 1.27 & 1.65 & 0.76 \\
\hline Married & $21.47 \pm 3.08$ & $24.28 \pm 3.22$ & $26.26 \pm 4.99$ & $39.11 \pm 9.94$ \\
\hline Unmarried & $22.89 \pm 3.37$ & $24.11 \pm 3.23$ & $26.68 \pm 5.21$ & $41.94 \pm 9.47$ \\
\hline $\mathrm{t}$ & $2.82 * *$ & 0.34 & 0.52 & 1.78 \\
\hline Only child & $20.57 \pm 3.29$ & $24.32 \pm 3.65$ & $26.62 \pm 4.86$ & $37.85 \pm 10.48$ \\
\hline Non-only child & $21.97 \pm 3.10$ & $24.23 \pm 3.12$ & $26.27 \pm 5.07$ & $39.99 \pm 9.76$ \\
\hline $\mathrm{t}$ & $2.78 * *$ & 0.15 & 0.43 & 1.35 \\
\hline Urban & $22.34 \pm 3.21$ & $24.50 \pm 3.15$ & $26.39 \pm 5.19$ & $41.34 \pm 9.52$ \\
\hline $\mathrm{t}$ & $2.79 * *$ & 1.11 & 0.15 & $2.50 * *$ \\
\hline
\end{tabular}


Table 2. Correlation analyses of positive psychological qualities and well-being

\begin{tabular}{|c|c|c|c|}
\hline & optimism & hope & self-efficacy \\
\hline Well-being & $0.42^{* *}$ & $0.40^{* *}$ & $0.47^{* *}$ \\
\hline
\end{tabular}

Table 3. Stepwise regression analysis of positive psychological qualities and well-being

\begin{tabular}{|c|c|c|c|c|c|c|c|c|}
\hline $\begin{array}{c}\text { Dependent } \\
\text { variable }\end{array}$ & $\begin{array}{c}\text { Predictive } \\
\text { variables }\end{array}$ & $\begin{array}{c}\text { Standard regression coefficient } \\
\text { Beta }\end{array}$ & t & sig. & F & sig. & $\mathrm{R}$ & $\mathrm{R}^{2}$ \\
\hline & (constant) & -1.41 & 0.160 & & & & & \\
\hline well-being & self-efficacy & 0.41 & 8.05 & 0.000 & 67.73 & 0.000 & 0.58 & 0.341 \\
\hline & optimism & 0.35 & 6.96 & 0.000 & & & & \\
\hline
\end{tabular}

Hope, self-efficacy and optimism were the independent variables and well-being was the dependent variable. The stepwise regression analysis was carried out. We can know that self-efficacy, optimism entered into the equation $(\mathrm{F}=67.73, \mathrm{P}<0.001)$, and explain rates of optimism and self-efficacy to well-being were $34.1 \%$, especially self-efficacy made the greatest contribution to the well-being and the explanation rate was $21.9 \%$. Regression equation can be established as follows: well-being $=-5.653+1.106$ self-efficacy +0.806 optimism

\section{Discussion}

\subsection{The current situation and influencing factors of enterprise staffs' positive psychological qualities and well-being}

Enterprise staffs' optimism, hope and self-efficacy scores were higher than the theoretical value. Well-being score was $(39.61 \pm 9.90)$ and it was close to 40 point which was the norm of Oxford Happiness Test-Revised (ROHS). The results of the present study showed that the current situation of the positive psychological qualities and well-being of the employees were in good level. But according to the previous researches on college students [10-13] with the single sample t-test, we found that employees' optimism $(\mathrm{t}=3.674, \mathrm{P}<0.001)$, hope $(\mathrm{t}=6.032$, $\mathrm{P}<0.001)$, well-being $(\mathrm{t}=5.702, \mathrm{P}<0.001)$ were lower than those of college students. This meant the positive psychological qualities of employees can be further improved and enterprises may learn from the practice of universities and colleges or adopt employee assistance program (EAP) to help employees develop their positive psychological qualities and well-being. International Association of employee assistance thought that EAP was available resources to enterprises and it can prevent, identify and solve the problems of person and productivity, and enhance the effectiveness of staff and workplace [14]. There were no significant differences between male and female in positive psychological qualities and well-being. In optimism, the score of unmarried was higher than married, non-only child was higher than only child, and towns was higher than countryside. Scheier et al. believed that the essence of optimism was the general expectation of positive events in the future [15]. That is to say, optimism was an individual's subjective state of mind or attitude, which was closely related to the expectations of the individual. For the same thing, different individuals had different cognitive assessments because of their different expectations. At the same time, optimism directed to the future, and it would have an important impact on the behavior of the present or future. From the results of the present study, the marital status, whether the only child, from urban or rural areas, all of them affected the individual's expectations which affected their mood or attitude. In well-being, the scores of urban staffs was higher than those of rural staffs. Now China is still a developing country, and regional development is not balance. There are better economic, social, educational resources in city and town than those in countryside, which might affect the feelings of well-being.

\subsection{The relationship between positive mental qualities and well-being of employees}

The present study found positive psychological qualities (optimism, hope and self-efficacy) of employees were all positively related with well-being. Regression analysis showed that optimism and self-efficacy were the keys to predicting well-being, and self-efficacy played more important role to it than optimism. Optimism regulated the cognitive level, so an optimistic person was more likely to learn promoting healthy habits and got more social support. Optimistic interpretation of style of life events was the key to promote the hope and optimism quality growth. Optimism can let a person see advantages of things, which may result in well-being. Some researches [16-18] believed that hope weakened the pain caused by the disease and body dysfunction in the physical aspects and made people believe that the current situation can be changed and enhance their encourage to face the dilemma in the psychological aspects and helped the patients maintain life, enhance the social adaptability of function, obtain more social support in social functions aspects. Hope strengthened one's positive emotions so as to enhance his or her well-being from the physical, psychological and social aspects. if someone has low self-efficacy to environmental effects, he or she inclined to having negative expectations and thought about too much potential difficulties which would lead to much psychological pressure, so that it made him or her pay more attention to the possibility of failure and adverse consequences instead of using his or her ability to achieve goals effectively. People who had a good sense of self-efficacy focused their attention and effort on the 
requirements of the situation and made greater efforts so as to enhance their well-being. Therefore, it was helpful to improve the well-being by enhancing the optimism, hope and self-efficacy of employees.

\section{Acknowledgments}

This research was supported by Ministry of education, the humanities and social sciences research project (University Ideological and political work) (16JDSZ2031); Zhanjiang philosophy and Social Sciences Planning Project (subject construction) (ZJ16GJ03)

\section{References}

1. L.L. Zhang, Relationship between subjective well-being, self-efficacy and job performance of employees. Master's degree thesis, Shenyang Normal University, (2013).

2. Y.L. Yu, J. Luo, The relationship between positive personality and psychological quality of college students. 3, 222-225 (2012).

3. Z.H. Zhang, C. Makowski, Design and kinetic study of a class of parallel mechanisms with three degrees of freedom. J. Mech. Eng. Res. Dev. 39, 433-440 (2016).

4. M. Scheier, C. Carver, M. Bridges, Distinguishing optimism from neuroticism (and trait anxiety, self-mastery and self-esteem): a re-evaluation of the Life Orientation Test. Journal of Personality and Social Psychology. 67, 1063-1078 (1994).

5. J.C. Lai, H.O. Cheung, W. Lee, H. Yu. The utility of the revised life orientation test to measure optimism among Hong Kong Chinese. International Journal of Psychology. 33, 45-56 (1998).

6. C.R. Snyder, C. Harris, J.R. Anderson, S.A. Holleran, L.M. Irving, S.T. Sigmon, et al., The will and the ways: Development and validation of an individual differences measure of hope. Journal of Personality and Social Psychology. 60, 570-585 (1991).
7. J. Ren, Positive Psychology. Shanghai: Shanghai Education Press, (2006).

8. C.K. Wang, Z.F. Hu, Y. Liu, The reliability and validity of the general self efficacy scale. Applied Psychology. 7, 38-40 (2011).

9. X. Zheng, Positive psychology-the science of human happiness and strength. Beijing: China Light Industry Press. 1, 7-10 (2008).

10. Y. Liu, Optimistic, social support, coping style and depression of college students. Master's degree thesis, Guangxi Normal University, (2009).

11. C. R. Chen, H. Y. Sheng, X. C. Li, The reliability and validity of the adult quality Hope Scale. Chinese Journal of clinical psychology. 17, 24-26 (2009).

12. Z.L. Liu, The groundwater pollution and environmental protection in China. Biotechnology: An Indian Journal, 10, 1883-1886 (2014).

13. Y.L. Yu, J.F. Tan, H.Z. Li, J. Luo, C.H. Wan, The relationship between medical students' subjective well-being and family care, Chinese Journal of behavioral medicine and brain science. 21(1), 66-68 (2012).

14. R. Zhao, Employee assistance program. Beijing: Science Press, 3, (2010).

15. M.F. Scheier, J.K. Weintraub, C.S. Carver, Coping with Stress: Divergent Strategies of Optimists and Pessimists. Journal of Personality and Social Psychology. 51(6), 1257-1264 (1986).

16. T. Matsushita, E. Matsushima, M. Maruyama, Psychological state, quality of life, and coping style in patients with digestive cancer. Gen Hosp Psychiatry. 27(2), 125 (2005).

17. W. Peng, et al., Separation of hemicelluloses from eucalyptus species: investigating the residue after alkaline treatment. Cellulose Chemistry and Technology. 49(9-10), 757-764 (2015).

18. U.S. Saleh, D.Y. Brockopp, Hope among patients with cancer hospitalized for bone marrow transplantation: a phenomenon logic study.Cancer Nurs. 24(4), 308 (2001). 